\title{
Reducing Environmentally Harmful Activities of the Company: PJSC "Obolon" (Production of Beer, Soft Drinks, Mineral Water, Spent Grain etc.)
}

\author{
Iryna Fedulova* and Tetiana Iakymchuk ${ }^{\dagger}$ \\ *PhD Economics, Department of Management, Kyiv National University of \\ Trade and Economics, Kyiv, Ukraine \\ †Senior Lecturer, Department of Management and Administration, National \\ University of Food Technologies, Kyiv, Ukraine
}

\section{Introduction}

The goal of PJSC "Obolon" is to meet the demands and expectations of customers and, as a result, to hold a leading market position. Their strategy includes constant attention to the preservation of the environment and takes into account the interests of all stakeholders. The basis of the strategy of "Obolon" is growth based on sustainable development principles.

As part of the strategy, "Obolon" implements innovative and energy-saving technologies, improves the environmental performance of production, minimizes harmful emissions into the environment, and reuses and recycles resources. In recent years, many investment projects aimed at reducing environmental impact were implemented - on the collection and recycling of PET bottles, processing of brewer's wet grains to get animal feedstuff for agriculture needs, reducing harmful emissions and ensuring prudent use of resources.

How to cite this book chapter:

Fedulova, I. and Iakymchuk, T. 2019. Reducing Environmentally Harmful Activities of the Company: PJSC "Obolon" (Production of Beer, Soft Drinks, Mineral Water, Spent Grain etc.). In: Gąsior, A. (ed.) Pro-ecological Restructuring of Companies: Case Studies, Pp. 109-120. London: Ubiquity Press. DOI: https://doi.org/10.5334/ bbk.i. License: CC-BY 4.0 
It has caused not only significant reduction of the impact on nature but also increased the eco-awareness and eco-culture of workers.

The company demonstrates a responsible attitude to environmental issues in Ukraine. The company is aware of its impact on the environment and, takes full responsibility towards the community, employees and shareholders. The corporation constantly improves production processes for resource conservation, and this creates considerable positive environmental effects as well as positive economic benefits.

\section{The Objective and Method}

According to the UN Global Compact in Ukraine, which is a voluntary initiative of socially responsible companies, "Obolon" regularly provides information on corporate social responsibility as a social report (Obolon Corporation, 2015). The social reports of the company were used in order to write the paper.

The objective of the paper is to determine the impact factors and discuss the environmental initiatives that were realized by "Obolon" to reduce the environmental impact, reduce the hazardous waste of production and to improve the reuse of materials. Analysis is the main method that should be used to obtain the objective. General scientific methods of analysis, such as methods of epistemology (analysis and synthesis); economic and logical methods for general analysis, such as methods of averages, methods of complex evaluation; and heuristic methods, such as questionnaires, were used in the paper.

After analyzing the environmentally harmful activities of the company, the most significant impact factors among economic, political, socio-cultural, technological, international and ecological factors were determined for "Obolon".

\section{Short History and Performance of the Company}

The establishment of the enterprise was dedicated to the Olympic Games in 1980. Czech professional men were engaged as experts, the world-famous masters of brewing. They chose the place for the new brewery. The main factor for the location of the building was the presence of huge reserves of soft and crystal clear water. Soon the company formed the largest corporation in Ukraine for the production of beer, low alcohol and soft drinks, and mineral water.

The structure of the corporation formed over many years under the influence of a development strategy aimed at diversification of production, switching to raw materials of its own production, innovation, absolute environmental safety and full social responsibility. The company "Obolon" incorporates the main plant, two separate workshops, two subsidiaries and four companies with corporate rights. Overall, the corporation employs approximately 7.5 thousand people. In 2014, the corporation entered to the top 20 of the largest employers in the agro-industrial complex. 
Table 1: Production indicators, million dal.

\begin{tabular}{|c|c|c|c|c|c|c|c|}
\hline \multirow[t]{2}{*}{ Indicators } & \multicolumn{5}{|c|}{ Year } & \multirow{2}{*}{$\begin{array}{c}\text { Difference } \\
(+/-) \text { of } \\
2014 \text { against } \\
2010\end{array}$} & \multirow{2}{*}{$\begin{array}{c}2014 \\
\text { against } \\
2010, \%\end{array}$} \\
\hline & 2010 & 2011 & 2012 & 2013 & 2014 & & \\
\hline Beer & 98.7 & 87.3 & 88.9 & 78.4 & 69.4 & -29.3 & 70.31 \\
\hline Low-alcohol drinks & 2.2 & 2 & 2.3 & 2.3 & 2.25 & 0.05 & 102.27 \\
\hline Soft drinks & 18.4 & 18.5 & 18.1 & 15.8 & 15.9 & -2.5 & 86.41 \\
\hline Mineral water & 9.0 & 7.2 & 6.8 & 5.5 & 5.5 & -3.5 & 61.11 \\
\hline
\end{tabular}

Source: Constructed by the author according to Obolon Corporation (2015).

The brewery has been making beer that has gained wide popularity. In 1989, "Obolon" became the first company among Soviet enterprises to export beverages to Europe and the USA. Its trademark, "Obolon", became recognized as traditional Ukrainian beer around the world. Nowadays, the share of "Obolon" in beer exports from Ukraine is $64.5 \%$.

Today, the beer market in Ukraine includes more than 400 species and varieties of beer, $90 \%$ of which are produced by the market leaders AB InBev, Carlsberg Ukraine and "Obolon". On the Ukrainian beer market, the market share of "Obolon" is about $21-25 \%$. The production indicators of the company from 2010 till 2014 are presented in Table 1.

The product portfolio of the corporation includes 10 name brands of beer, seven low-alcohol beverages, seven soft drinks, six waters etc. In the structure of domestic production, $49 \%$ of the products are manufactured in PET, $35 \%$ in glass bottles, $12 \%$ in kegs and $4 \%$ in metal cans.

The activities of the company in recent years allowed the company to obtain some financial results (presented in Table 2) that have contributed to the implementation of measures to preserve the environment.

The company has confirmed compliance with the management systems that operate in the corporation "Obolon": Quality management system (ISO 9001: 2008); Food safety management systems (ISO 22000: 2005); Environmental management systems (ISO 14001: 2004); and Occupational health and safety assessment scheme (OHSAS 18001: 2007).

\section{Reducing Environmentally Harmful Activities of the Corporation}

The basis for the continuous improvement of environmental protection is environmental programs that are the part of the enterprise's policy. The main environmental programs of the company are connected with gradual reduction of discharge (emissions) into the air; rational usage of resources; and the 


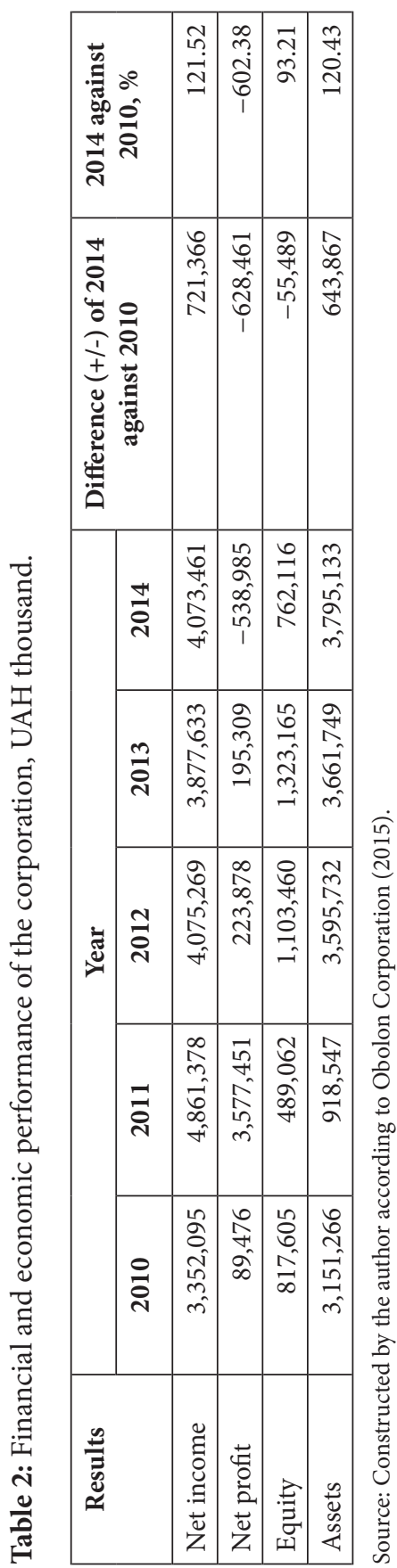


maximum possible recycling of production waste. The main environmental programs of the company and their results are considered below.

\section{Gradual reduction of emissions into the air and other pollution}

There is yearly reduction of emissions by the corporation (Table 3 ).

Atmospheric emissions were reduced by $14 \%$ in 2014 compared to the previous year. In particular, nitrogen compounds, grain dust and carbon oxide were reduced in 2014 compared to the previous year.

There is a constant reduction of pollution in the environment at the corporation, including waste water (Table 4 ).

Waste water was reduced by $24 \%$ in 2014 compared to 2010 and by $7.9 \%$ compared to the previous year.

\section{Rational usage of resources}

As a result of the implementation of a number of energy efficiency and savings measures, the corporation's impact on the environment has been continuing to decline. The corporation's consumption of natural gas in 2012 was equal to 26,826 thousand $\mathrm{M}^{3}$; in 2013 it was 23,708 thousand $\mathrm{M}^{3}$; in 2014 it was 18,544

Table 3: Reduction of atmospheric emissions, tons.

\begin{tabular}{|l|r|r|r|r|}
\hline \multirow{2}{*}{ Year } & \multicolumn{3}{|c|}{ Emissions } & \multirow{2}{*}{ Total } \\
\cline { 2 - 4 } & Nitrogen compounds & \multicolumn{1}{|c|}{ Grain dust } & Carbon oxide & \\
\hline 2010 & 29.95 & 12.6 & 0.42 & 44 \\
\hline 2011 & 29.6 & 11.3 & 0.51 & 45 \\
\hline 2012 & 24.04 & 9.9 & 0.45 & 37 \\
\hline 2013 & 18.6 & 10.79 & 0.76 & 33 \\
\hline 2014 & 17.3 & 9.5 & 0.64 & 30 \\
\hline
\end{tabular}

Source: Constructed by the author according to Obolon Corporation (2015).

Table 4: Reducing pollution of the company, million litres.

\begin{tabular}{|l|c|r|r|r|r|}
\hline \multirow{2}{*}{\multicolumn{1}{|c|}{ Indicators }} & \multicolumn{5}{c|}{ Years } \\
\cline { 2 - 7 } & $\mathbf{2 0 1 0}$ & $\mathbf{2 0 1 1}$ & \multicolumn{1}{c|}{$\mathbf{2 0 1 2}$} & \multicolumn{1}{c|}{$\mathbf{2 0 1 3}$} & \multicolumn{1}{c|}{$\mathbf{2 0 1 4}$} \\
\hline Waste water & 2198 & 2121 & 2175 & 1810 & 1667 \\
\hline In \% to previous year & - & 96.5 & 102.5 & 83.2 & 92.1 \\
\hline
\end{tabular}

Source: Constructed by the author according to Obolon Corporation (2015). 
thousand $\mathrm{M}^{3}$. Thus, consumption of natural gas was reduced by $27 \%$ in $2014 \mathrm{com}$ pared to 2013. It is enough volume for cooking and heating for 1247 Ukrainian families throughout the year. In addition, beverage production of all categories decreased by $10 \%$ in 2014 compared to the previous period and by $30 \%$ compared to 2010. Accordingly, this decrease in production has reduced usage of resources.

In order to reduce the dependence on energy resources, regional enterprises of "Obolon" in Okhtyrka (Sumy Region) and in Fastiv (Kyiv Region) set up solid fuel boilers. Wood waste (sawdust, broken pallets, boxes and so on) are used as the fuel. Three to four kilograms of burned wood waste give $0.008 \mathrm{Gcal}$ of heat as well as $1 \mathrm{~m}^{3}$ of gas. The system of solar collectors for water heating in the administrative building was established at the "Obolon" brewery and at production sites of Zibert's Brewery Subsidiary in the city of Fastiv.

On a global average, five litres of water are used to produce one litre of beverages. The company "Obolon" requires 2.7 litres of water for the production of one litre of beverages and no more than 3.5 litres for beer production. Water consumption in the corporation was equal to 3781 thousand $\mathrm{M}^{3}$ in 2012; in 2013 it was 3241 thousand $\mathrm{m}^{3}$; in 2014 it was 2633 thousand $\mathrm{m}^{3}$. Thus, water consumption decreased by $23 \%$ in 2014 compared to 2013 . This volume is equal to 242 standard Olympic-sized swimming pools. Repeated consumption of water used for washing equipment and glass bottles was equal to 1074 thousand $\mathrm{M}^{3}$ in 2012; in 2013 it was 3241 thousand $\mathrm{M}^{3}$; in 2014 it was 2998 thousand $\mathrm{M}^{3}$.

Steam consumption in the corporation was equal to 201,094 Gcal in 2012; in 2013 it was 179902 Gcal; in 2014 it was 149650 Gcal. By using an energy conservation system the secondary steam is formed during the boiling of beer wort and returned to the production cycle. Thus, the usage of steam decreased by $20 \%$ in 2014 compared to the previous period. The usage of secondary steam was equal 2630 tons in 2012 year; in 2013 it was 2140 tons; in 2014 it was 1807 tons.

Electricity consumption in the corporation was equal to 309,046 GJ in 2012; in 2013 it was 275,832 GJ; in 2014 it was 195,397 GJ. Thus, "Obolon” reduced electricity consumption by $30 \%$ in 2014 . For this purpose, the company implemented the following measures:

- Installed equipment for additional utilization of heat in the boiler-house.

- Installed 197 LED-lamps.

- In 2010, joined the global eco-initiative "Earth Hour" of the World Wildlife Fund for Nature (WWF). The company has showed concern for environmental problems more than five years. In 2014, the company saved about $300 \mathrm{~kW}$ of electricity in the frame of the initiative.

\section{Maximum possible recycling of production waste}

Today there is no legislative framework that would stimulate the recycling of waste in Ukraine. There are no effective incentives in the state for people to sort 
waste; there are no conditions for waste recycling and there is no waste management system. So "Obolon" launched its own program of recycling of plastic waste in 2003. The plastic waste (PET bottles) is the main threat to the environment because the decay period of plastic in nature is more than 400 years. Specialists state that the popularity of products in PET packaging (beer, beverages, household chemicals, etc.) is growing - this segment grows by $10-12 \%$ every year. The specific waste formation of the company is presented in Table 5.

Specific waste formation was reduced by three times during the manufacture of beverages from 2010 to 2014 .

Recycling of waste at the company includes: internal recycling and reuse, waste disposal and third-party recycling (Table 6).

Internal recycling and reuse of materials as secondary raw materials in the production include: realisation of organic waste for feeding animals (brewer pellet, bran), plastic waste and so on. The examples of projects on recycling of waste that were realized by the company are considered below:

1. The company recycles carbon dioxide $\left(\mathrm{CO}_{2}\right)$ from gas fraction to liquid and then uses it in production. $\mathrm{CO}_{2}$ is formed during brewery fermentation. Processing plants to get $\mathrm{CO}_{2}$ are in Kyiv ("Obolon") and in Fastiv, Kyiv region (Zibert's Brewery). Re-use of $\mathrm{CO}_{2}$ was equal to 11,922 tons in 2012; in 2013 it was 11,674 tonnes; in 2014 it was 11378 tonnes.

Table 5: Specific waste formation of the company.

\begin{tabular}{|l|r|r|r|r|r|}
\hline \multirow{2}{*}{ Indicators } & \multicolumn{5}{|c|}{ Year } \\
\cline { 2 - 6 } & $\mathbf{2 0 1 0}$ & $\mathbf{2 0 1 1}$ & $\mathbf{2 0 1 2}$ & $\mathbf{2 0 1 3}$ & $\mathbf{2 0 1 4}$ \\
\hline Useful product, tons/thousand dal & 99.56 & 99.65 & 99.65 & 99.83 & 99.87 \\
\hline Specific waste formation, tons/thousand dal & 0.44 & 0.35 & 0.35 & 0.17 & 0.13 \\
\hline
\end{tabular}

Source: Constructed by the author according to Obolon Corporation (2015).

Table 6:Wastes of the Company and their Distribution.

\begin{tabular}{|l|r|c|c|r|r|}
\hline \multirow{2}{*}{ Indicators } & \multicolumn{5}{c|}{ Year } \\
\cline { 2 - 6 } & \multicolumn{1}{|c|}{$\mathbf{2 0 1 0}$} & \multicolumn{1}{c|}{$\mathbf{2 0 1 1}$} & $\mathbf{2 0 1 2}$ & \multicolumn{1}{c|}{$\mathbf{2 0 1 3}$} & \multicolumn{1}{c|}{$\mathbf{2 0 1 4}$} \\
\hline $\begin{array}{l}\text { Recycling waste by the } \\
\text { company, tons }\end{array}$ & 169,200 & 170,300 & 156,592 & 134,614 & 129,839 \\
\hline Distribution of waste depending on recycling, \%: & & & & \\
\hline Internal recycling and reuse & 94.1 & 94.8 & 94.5 & 94.1 & 95.2 \\
\hline Waste disposal & 4.3 & 3.7 & 3.6 & 4.1 & 2.9 \\
\hline Third-party recycling & 1.6 & 1.5 & 1.9 & 1.8 & 1.9 \\
\hline
\end{tabular}

Source: Constructed by the author according to Obolon Corporation (2015). 
2. The innovative line on recycling of PET packaging has been established in Alexandria (Kirovohrad region). The Kirovograd region was the ideal location for the project in terms of logistics and equidistance from major cities.

Today "Obolon" independently collects raw materials (in production units installed over a hundred containers to collect used bottles) and buys used PET packaging from suppliers. The company's project to recycle of PET packaging has been going on for 12 years in Alexandria. Nine thousand tons of used bottles were recycled in the first 10 years of the project. Thirty million units of PET containers annually come to recycling and 2.5 million PET bottles are processed at the enterprise every month.

The effects from the project to recycle of plastic bottles include the following:

- Proceeds from the sale of binding band were equal to 10.2 million UAH in 2013.

- Provides recycling of plastic bottles.

- Improves the environment through reducing the accumulation of plastic in nature.

- Allows for production of new materials from waste.

- Creates new jobs - more than 350 jobs.

- Promotes eco-culture among the production companies.

The problems at hand include low culture of the collection of plastic waste among the population and some problems connected with collecting of plastic waste.

3. One of the main problems of the beer industry is the utilization of organic waste generated in the production process. Thirty million tons of such waste are produced in the world each year.

Most organic waste (brewer pellet, malt sprouts and yeast) traditionally are used in agriculture. The shelf life of most organic waste, for example brewer pellet, is short and because of it their logistics are limited. However, in the environmentally responsible companies, waste can go from costly budget items to income-generating items if they properly organise the issue of recycling.

The corporation "Obolon" was the first company in Ukraine to begin processing brewer pellet. The equipment for production of dry pellets can process up to 700 tons per day without harmful effects on the environment. The corporation "Obolon" had difficulties for some time with processing brewer pellet through large volumes of its formation. In 2008, the company introduced a project to dry brewer's wet grains. It solves the main problem - to increase the shelf life of brewer pellet to six months and expand its logistics.

The drying process requires a significant amount of energy. Therefore, the corporation implemented the project on reconstruction of a heat supply system in 2011 in order to reduce the energy intensity of production. So, now "Obolon" partly uses secondary pairs with $100 \%$ return condensate to the boiler for 
drying of brewer's wet grains. It saves about 35 thousand $\mathrm{m}^{3}$ of natural gas per month. "Obolon"'s main brewer pellet customers are the dairy farms of Ukraine (Association of milk in Ukraine) as well as farmers from the EU and Israel.

The effect from the project on processing of brewer pellet includes the following:

- Significant reduction of waste formation of brewer's wet grains - by $91 \%$ in five years.

- Improvement of the sanitary state of the territory.

- Reduction of emissions into the air (exhaust gases) from automobile transportation as a result of reducing the number of shipping operations of brewer's wet grains.

Thus, every year the company works to improve its efficiency and responsible use of resources, financing measures for environmental protection. Recently there was decline in production, and as a result "Obolon" suffered a reduction in its economic indicators. In particular, in 2014 the company received a loss 538,985 thousand UAH. However, the work on improving the environmental performance of the enterprise does not stop. This is shown by the costs for environmental activity (Table 7).

The costs for environmental protection in the corporation include:

- operating costs for environmental protection: purchase of raw materials for maintenance of environmental protection equipment;

- capital investment to install the equipment of high efficiency; and

- fees for the services of environmental character on recycling of certain types of waste.

Environmental impacts that are caused by the introduction of new activities, products and processes are assessed in advance and are always minimized.

The influence of corporations on the environment is constantly monitored, documented and analyzed. According to the company's data, the proportion of reused water at "Obolon" is growing, and now more than $70 \%$ of

Table 7: The costs for environmental protection in the corporation.

\begin{tabular}{|l|r|r|r|r|c|}
\hline \multicolumn{1}{|c|}{ Year } & \multicolumn{1}{|c|}{$\mathbf{2 0 1 0}$} & \multicolumn{1}{c|}{$\mathbf{2 0 1 1}$} & $\mathbf{2 0 1 2}$ & \multicolumn{1}{c|}{2013} & $\mathbf{2 0 1 4}$ \\
\hline $\begin{array}{l}\text { Investments in environment } \\
\text { protection, million UAH }\end{array}$ & 23.6 & 15.3 & 19.5 & 16.0 & 10.0 \\
\hline $\begin{array}{l}\text { The costs for environmental } \\
\text { activity, in \% of net income }\end{array}$ & 0.70 & 0.31 & 0.48 & 0.41 & 0.25 \\
\hline
\end{tabular}

Source: constructed by the author according to Obolon Corporation (2015). 
the water is used again. "Obolon" recycles and reuses more than $96 \%$ of the production residue.

Introducing measures to reduce the harmful impact of activities on the environment was related to the following:

- Reliable relationships with suppliers and customers with the absolute performance of regulatory, legal requirements and contractual obligations.

- Desire to be the best in the field of quality, product safety and attitude towards the environment and to reduce occupational risks for staff and the people on the spot.

- Ensure increasing degree of employees' motivation and satisfaction of customers and other stakeholders.

- Use of modern equipment minimizes harmful emissions into the environment and decreases some production costs.

- The ability to save and to release additional resources.

\section{Conclusions}

"Obolon" seeks and uses innovative ways to minimize the harmful effects of their activity on the environment every day. They achieve this by reducing costs from saving energy, water and other resources, and increasing amounts of recyclable waste in their factories.

Table 8 demonstrates the influence of factors on the corporation "Obolon" in the context of reducing environmentally harmful activities and its ability to implement a restructuring process.

The above economic factors determine the financial condition of the enterprise and the impact on the restructuring process; it is not possible for other beer companies with a weak market position to participate in environmental programs and projects without financial support.

Among the political and legal aspects of the international market, "protection of the environment" impacts the company because "Obolon" is a modern enterprise that seeks to meet the international standards of activity, product quality and environmental protection.

Among the socio-cultural factors the biggest impact was made by factors 24 and 26. Today there are some changes in the population's awareness and attitude towards the environmental situation in the country. It is a gradual and slow process of changes connected with different factors and with the educational level too. The level of education in Ukraine is high, and there is environmental education at all levels of learning, from the first class to masters' course. More and more information is emerging about protection and preservation of the environment in other countries and the consequences that may occur if we consciously avoid such activities. 
Table 8: Impact factors on the restructuring processes of the enterprise.

\begin{tabular}{|c|c|c|}
\hline No & Determinant & Impact \\
\hline 1 & 2 & 3 \\
\hline \multicolumn{3}{|c|}{ Economic factors } \\
\hline 2 & Inflation rate & 10 \\
\hline 3 & The national currency exchange rate & 10 \\
\hline 8 & Competition on core market & 8 \\
\hline 9 & Consumer confidence & 7 \\
\hline \multicolumn{3}{|c|}{ Political and legal aspects of the international market } \\
\hline 22 & Protection of the environment & 8 \\
\hline \multicolumn{3}{|c|}{$\begin{array}{l}\text { Socio-cultural factors in both the national and international sense, and the } \\
\text { relationships between them }\end{array}$} \\
\hline 24 & $\begin{array}{l}\text { The civilization progress (lifestyle and its changes, knowledge of the } \\
\text { living standards in other countries) }\end{array}$ & 5 \\
\hline 26 & The level of education & 5 \\
\hline \multicolumn{3}{|c|}{ The technological factors } \\
\hline 35 & The level of technological modernity industry & 6 \\
\hline 36 & New inventions and development of science & 6 \\
\hline \multicolumn{3}{|c|}{ International factors } \\
\hline 42 & The international agreements and regulations & 7 \\
\hline \multicolumn{3}{|c|}{ Ecological aspects } \\
\hline 49 & $\begin{array}{l}\text { Permanent monitoring of water consumption (e.g. control of } \\
\text { leaking taps) }\end{array}$ & 7 \\
\hline 52 & Ecological innovations & 6 \\
\hline 53 & $\begin{array}{l}\text { Encouraging environmental awareness of employees and business's } \\
\text { stakeholders }\end{array}$ & 7 \\
\hline
\end{tabular}

Source: Constructed by the author.

Among the technological factors, the most important for the company are the factors 35 and 36. The company is engaged in scientific research and development but there is no research laboratory. Therefore, monitoring domestic and international developments that can be effectively used for restructuring and reuse of resources and usage of alternative energy sources and increasing waste production is important for the company. The achievements of modern science and technology in this direction are an impetus for the environmental activity of the company. 
Among international factors, "international agreements and regulations" are significant, because the company carries out export operations and adheres to international business standards. Among the environmental aspect factors, 49, 52 and 53 are important, as the environmental initiatives of "Obolon" are connected with effective use and reuse of resources, alternative sources of energy and increasing level of waste-free production.

Future prospects of environmental focus for "Obolon" will be connected with increasing volumes of PET bottles processing at the company; with further reduction of air emissions and waste water, reduction of specific waste during the manufacture of beverages.

\section{References}

PJSC “Obolon”, Sustainable Development Report of Obolon Corporation, 2015. Available at, http://report.obolon.ua [Last accessed 20 September 2016]. 